
Research

\title{
Treatment plan comparison in acute and chronic respiratory tract diseases: an observational study of doxophylline vs. theophylline
}

\author{
F. S. Mennini, P. Sciattella, A. Marcellusi, A. Marcobelli, A. Russo \& A. P. Caputi
}

To cite this article: F. S. Mennini, P. Sciattella, A. Marcellusi, A. Marcobelli, A. Russo \& A. P. Caputi (2017): Treatment plan comparison in acute and chronic respiratory tract diseases: an observational study of doxophylline vs. theophylline, Expert Review of Pharmacoeconomics \& Outcomes Research, DOI: 10.1080/14737167.2017.1301815

To link to this article: http://dx.doi.org/10.1080/14737167.2017.1301815

Accepted author version posted online: 03

Mar 2017.

Published online: 15 Mar 2017.

Submit your article to this journal 지

Џ Article views: 2

Q View related articles

View Crossmark data $[\pi$ 


\title{
Treatment plan comparison in acute and chronic respiratory tract diseases: an observational study of doxophylline vs. theophylline
}

\author{
F. S. Mennini ${ }^{a, b}$, P. Sciattella ${ }^{a, c}$, A. Marcellusi ${ }^{a, b, d}$, A. Marcobellie, A. Russo ${ }^{f}$ and A. P. Caputi ${ }^{f}$
}

aEconomic Evaluation and HTA (EEHTA), CEIS, Faculty of Economics, University of Rome "Tor Vergata", Rome, Italy; 'bnstitute of Leadership and Management in Health - Kingston University London, London, UK; 'Department of Statistical science, "Sapienza" University of Rome, Rome, Italy;

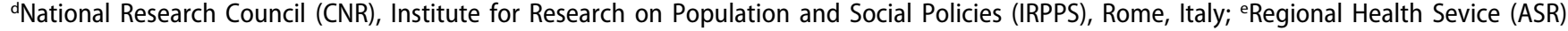
Marche, Ancona, Italy; ${ }^{\text {DDepartment }}$ of Clinical and Experimental Medicine, University of Messina, Messina, Italy

ABSTRACT

Background: The main objective of this article is to estimate the global cost related to the use of the two drugs (associated drugs, specialist visits, hospital admissions, plasma drug monitoring).

Methods: The drug prescriptions were extracted from the Information System of the Pharmaceutical Prescriptions of the Marche Region for each ATC code in the years 2008-2012 and the number of patients per year and other outcomes measure were obtained.

Results: 13,574 patients were treated with theophylline and 19,426 patients with doxophylline. The number of patients treated was approximately 5,000 per year. Co-prescription with other drugs, use of corticosteroids, mean number of visits and hospital admissions (per 100 patients) were lower for doxophylline vs theophylline (1.55vs5.50, $0.3 \mathrm{vs} 0.7,2.05 \mathrm{vs} 3.73$ and $1.57 \mathrm{vs3} .3$ respectively). The annual mean cost per patient was $€ 187.4$ for those treated with doxophylline and $€ 513.5$ for theophylline.

Conclusions: In our study, doxophylline resulted to be associated with a reduction of the overall cost.
ARTICLE HISTORY

Received 28 July 2016

Accepted 28 February 2017

\section{KEYWORDS}

Claims database; cost analysis; economic analysis; real world data; cost management

\section{Introduction}

Today asthma and chronic obstructive pulmonary disorders (COPD) represent the second most common disease in the Western world, with a $10 \%$ prevalence in the adult population [1] and a growing incidence due to both population aging and environmental pollution [2-5].

The number of effective drugs that reduce the symptoms and bronchoconstriction increased in the last years [6]. Among the drugs included in the guidelines of these diseases, methylxanthines were an effective tool to reduce the symptoms and prevent bronchoconstriction for a long time [7]. However, due to the introduction of other drugs, they are now considered secondary with respect to other treatments.

Doxophylline is a second-generation methylxanthine, different from theophylline (and aminophylline) due to a dioxolane group in the molecule [8]. The bronchodilator activity of doxophylline was demonstrated in animal studies $[9,10]$ and later in controlled clinical trials $[11,12]$ that brought to its registration and launch on the market in the 1980s. The clinical development of doxophylline boosted in the following years, when a series of randomized double-blind clinical studies was conducted [13].

However, as the regulation in force when the drug was registered did not require randomized double-blind protocols in clinical trials, a summary of product characteristics (SPC) for all methylxanthines on the market was approved, concerning overlapping effectiveness, safety, and precautions.
The studies conducted on the drug highlighted particular characteristics of doxophylline, consisting in bronchodilator effects that basically overlap to those of the main methylxanthines on the market (theophylline and aminofylline), with a lower incidence of side effects [14]. This improved tolerability of the molecule seems to be especially due to a reduced incidence of adverse effects on the gastrointestinal [15], cardiovascular [16], and central nervous systems [17].

These different characteristics brought Page [18] to propose doxophylline as the first of a new class of drugs named 'novofyllines'. From a pharmacokinetics point of view, doxophylline differs from theophylline for the lack of interferences with cytochromes CYP1A2, CYP2E1, CYP3A4, preventing significant interaction with other drugs. The particular tolerance of doxophylline justifies the drug's safety. This is why it is not necessary to proceed to the plasma monitoring of its concentration as it occurs with theophylline and aminofylline. These differences with theophylline are not reported on the SPC. Therefore, the prescribing physician who does not refer to literature or is not updated may believe that the two drugs are comparable.

In light of this, the use of doxophylline (anatomical therapeutic chemical classification (ATC): R03DA11) and theophylline (ATC: R03DA04) in an Italian region was analyzed, estimating the direct costs of the two treatments in real practice. Theophylline has an average base price lower than doxophylline ( $€ 4.81$ vs $€ 6.37$ per prescription). 


\section{Methods}

The main flow sources of the Marche region were analyzed. The pharmaceutical prescriptions for adult patients reported on all the prescriptions sent by municipal and private pharmacies of the region, reimbursed by the National Health Service (NHS) (class A drugs), were extracted by the Information System of the Pharmaceutical prescriptions of the Marche region.

Through the marketing authorization code (AIC) that identifies the active ingredient (ATC code) it was possible to find the patients to whom the concerned drugs were administered. In the specific database for each prescription, the date of drug administration and the patient's personal information were reported and made anonymous by means of a unique code.

The analysis identified two groups of patients who were inquired retrospectively and enrolled in the analysis through the respective ATC codes (R03DA04 and R03DA11). Through this selection, the number of prescriptions made over the period 1 January 2008 and 31 December 2012 was estimated. Later it was possible to trace back the number of 'users'.

The yearly number of prescriptions was obtained selecting all the prescriptions by single active ingredient prescribed in the monitoring period. The number of users was estimated identifying the subjects who received at least one prescription of ATC in the trial period.

To estimate the days of treatment, 5 days of treatment with syrup (AIC 011226091 for theophylline and AIC 025474065 and 033887047 for doxophylline) were assumed, together with 10 days of treatment with tablets (all the other AICs).

Furthermore, the drugs that could be associated with enrolment ATCs and that were part of the asthma therapy were identified. The concomitant prescriptions were estimated selecting all the ATC prescriptions that were identified as potentially associated with the following main active ingredients being studied:

R03AC (selective agonists of the beta-2 adrenergic receptors), R03AK (adrenergics and other drugs for obstructive respiratory syndromes), R03BA (glucocorticoids), R03BB (anticholinergics), R03CC (selective agonists of beta-2 adrenergic receptors), and R03DC (antagonists of leukotrienes receptors).

Through a record linkage procedure, the identified prescriptions were associated with previously extracted prescriptions for theophylline and doxophylline, through the anonymous code identifying the user.

To define the 'concomitant therapy', an interval of \pm 30 days was identified from the prescription of theophylline or doxophylline and a prescription of one of the associated active ingredients.

As far as the prescription price is concerned, the 'price' information contained in the prescription record was used, without taking into account the information related to the amount to be paid by the patient.

The linkage to the patient also allowed to identify the hospital admissions of each therapeutic group. Specifically, the hospital admissions that were registered in the hospital register over the period 2008-2012, within the calendar year from the first prescription observed, were taken into account. The hospital admissions considered in this analysis had to be associated with asthma or COPD or possible adverse events related to the treatment, identifying the Diagnosis-Related Groups (DRGs) reported in Note 1.
Also in this case, the calculation was made at reimbursement rates associated with the DRG required by NHS and included in the regional database.

Finally, the specialist visits potentially associated with the patients under therapy included in the analysis were considered. In particular, the codes reported in the range of fees indicated in Note 2 were selected.

Through the anonymous linking code, total and average costs per patient treated with each type of treatment were estimated. In particular, the costs were broken down by drug cost (doxophylline and theophylline), cost of associated drugs, cost of glucocorticoids (ATC R03BA), cost of monitoring with theophyllinemia (cod. 90.41.2), and cost of other specialist visits.

For each subject, clinical history was defined by retrieving specific conditions recorded during hospitalizations in the 2 years previous the first prescription. The conditions analyzed were cancer, diabetes, lipid metabolism disturbances, obesity, blood disorders, hypertension, thyroid gland disorders, ischemic diseases, heart failure, chronic pulmonary heart disease, neurological and muscular diseases, systemic diseases, digestive system diseases, other heart conditions, conduction disturbances and arrhythmias, cerebrovascular disease, mental and psychiatric disorders, acute chronic respiratory conditions, chronic respiratory diseases, and chronic renal disease (ICD9 CM codes in Note 3).

The association between drugs and concomitant therapy, hospitalizations, and specialist visits were studied using Poisson regression models (risk ratio (RR)) adjusting for age, sex, and risk factors. A stepwise bootstrap procedure was adopted in order to select statistically significant confounding variables.

Concomitant therapy was defined as one prescription of the associated active ingredients within 30 days after the first prescription of theophylline or doxophylline.

Regarding hospitalization admissions, it was considered all hospitalizations within 1 year from first drug prescription. Specialist visits were defined as the visits within 60 days from first prescription.

The analysis of costs was performed stratifying for age and sex.

Differences between two treatment groups were tested using $\mathrm{t}$-test for continuous variables and $\mathrm{x}^{2}$ test for categorical variable, and a $p$-value lower than 0.05 was considered statistically significant.

\section{Results}

In the Marche region, out of 1,555,560 individuals (mean of resident population 2008-2013, source Istat), 32,998 were suspected of being affected from asthma and COPD on the basis of xanthine prescription.

Based on the heterogeneity of the patients being treated in the two groups of drugs, the results are reported in the following sections.

\subsection{Total population considered based on the prescription of the two drugs}

As reported in Table 1, 13,574 patients being treated with theophylline who received 94,454 prescriptions and 19,424 patients being treated with doxophylline who received 62,791 prescriptions were identified. 
Table 1. Analyzed sample.

\begin{tabular}{lcccc}
\hline ATC & Year & Patients & Prescriptions & Boxes \\
\hline Theophylline & 2008 & 6,258 & 24,893 & 39,214 \\
& 2009 & 5,473 & 21,928 & 34,643 \\
& 2010 & 4,502 & 18,283 & 29,049 \\
& 2011 & 3,954 & 15,797 & 24,986 \\
Total & 2012 & 3,376 & 13,553 & 21,558 \\
Doxophylline & $\mathbf{2 0 0 8 - 2 0 1 2}$ & $\mathbf{1 3 , 5 7 4}$ & $\mathbf{9 4 , 4 5 4}$ & $\mathbf{1 4 9 , 4 5 0}$ \\
& 2008 & 6,278 & 14,639 & 21,753 \\
& 2009 & 6,218 & 14,112 & 20,631 \\
& 2010 & 5,615 & 12,825 & 18,443 \\
& 2011 & 5,123 & 11,373 & 16,340 \\
Total & 2012 & 4,289 & 9,842 & 14,233 \\
& $\mathbf{2 0 0 8 - 2 0 1 2}$ & $\mathbf{1 9 , 4 2 4}$ & $\mathbf{6 2 , 7 9 1}$ & $\mathbf{9 1 , 4 0 0}$ \\
\hline
\end{tabular}

Both drugs were mainly used in the elderly population. However, the percentage of use is higher for doxophylline up to 75 years of age and reverses in the older population (Figure 1). The mean age for theophylline is 73 years, while for doxophylline is 67 (t-test $p<0.001$ ). Analyzing the distribution by sex (Figure 2), it may be observed that doxophylline is more prescribed in the female population in both age segments.

\subsection{Co-prescriptions associated with the two drugs}

In the total population of patients treated with methylxanthines, the risk of co-prescription was lower for patient treated with doxophylline compared with theophylline $\left(\mathrm{RR}_{\mathrm{adj}}\right.$ 0.84; 95\% Cl 0.78-0.90).

The average number of co-prescriptions per patient is equal to 5.50 for theophylline and $\mathbf{1 . 5 5}$ for doxophylline, with a $71.7 \%$ reduction of co-prescriptions (Figure 3 ).

Considering that polypharmacotherapy prevails in the elderly population (over 65), in the population treated with methylxanthines, the average number of co-prescriptions per patient is

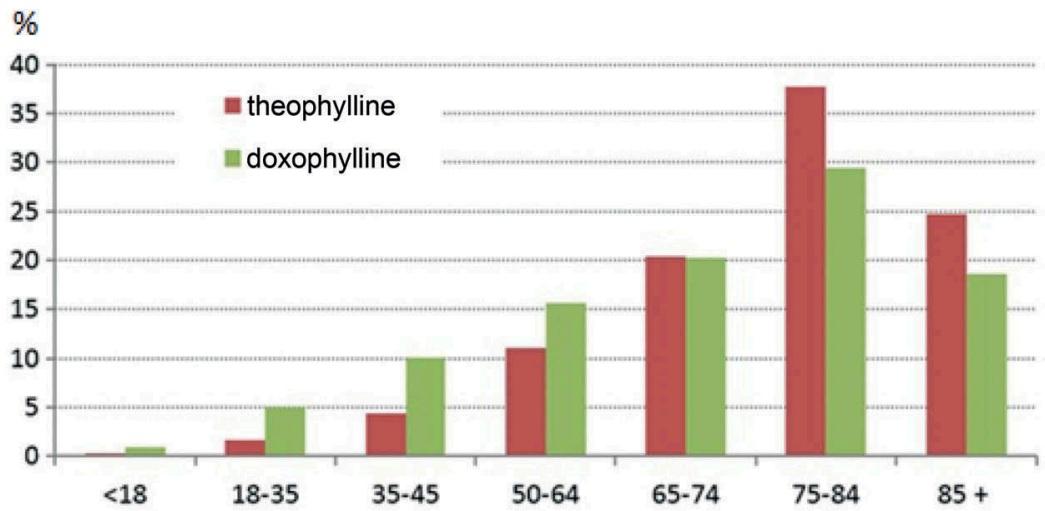

Figure 1. Percentage of use (by age segment) of doxophylline and theophylline.

(a) Total population

theophylline

- Males - Females

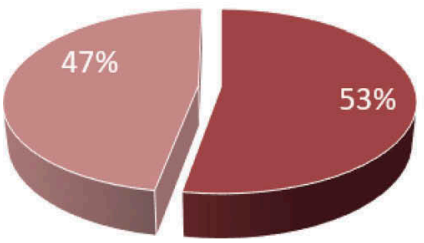

doxophylline

- Males $n$ Females

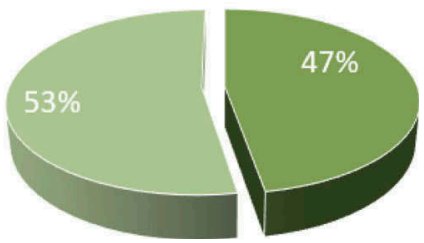

(b) Patients over 65

theophylline

- over 65 Males Over 65 Females

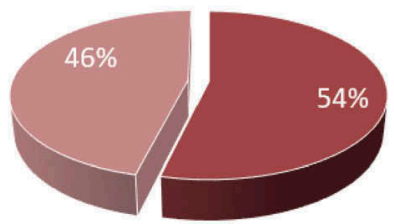

doxophylline

- over 65 Males $=$ Over 65 Females

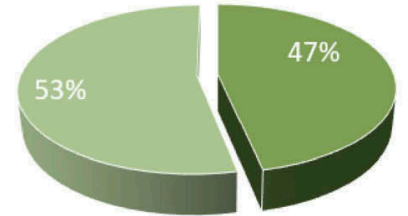

Figure 2. Distribution by sex according to the treatment ((a) Total population; (b) Patients over 65) - Marche Region 2008-2012. 
(a) Number of services (total population)

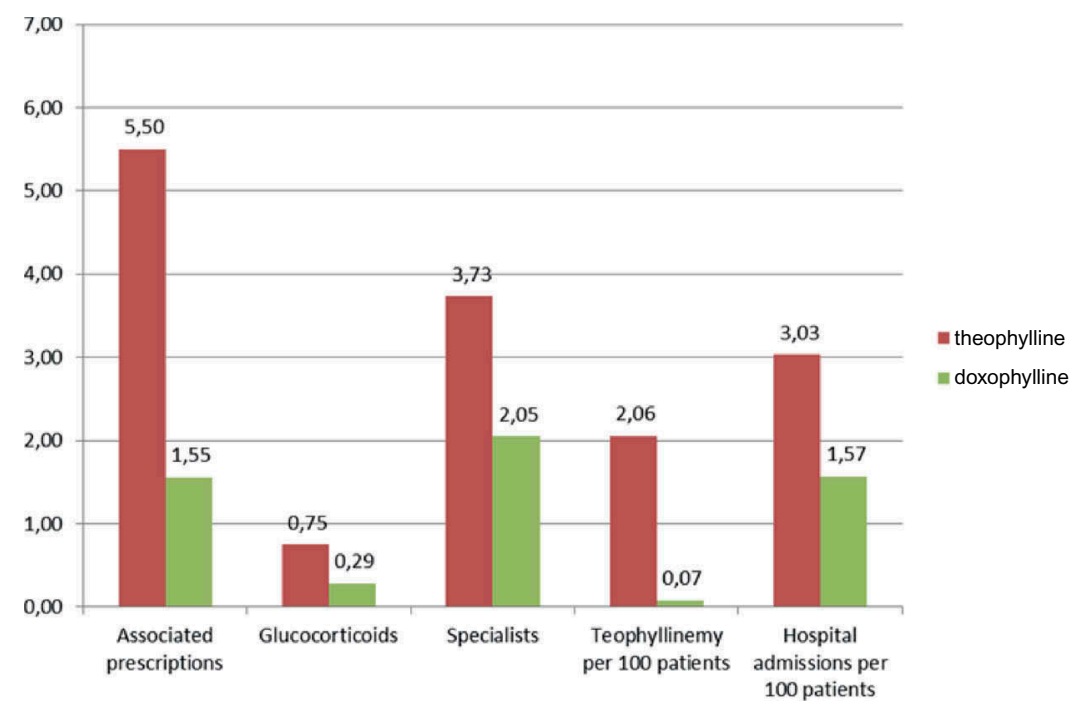

(b) Number of services (over 65)

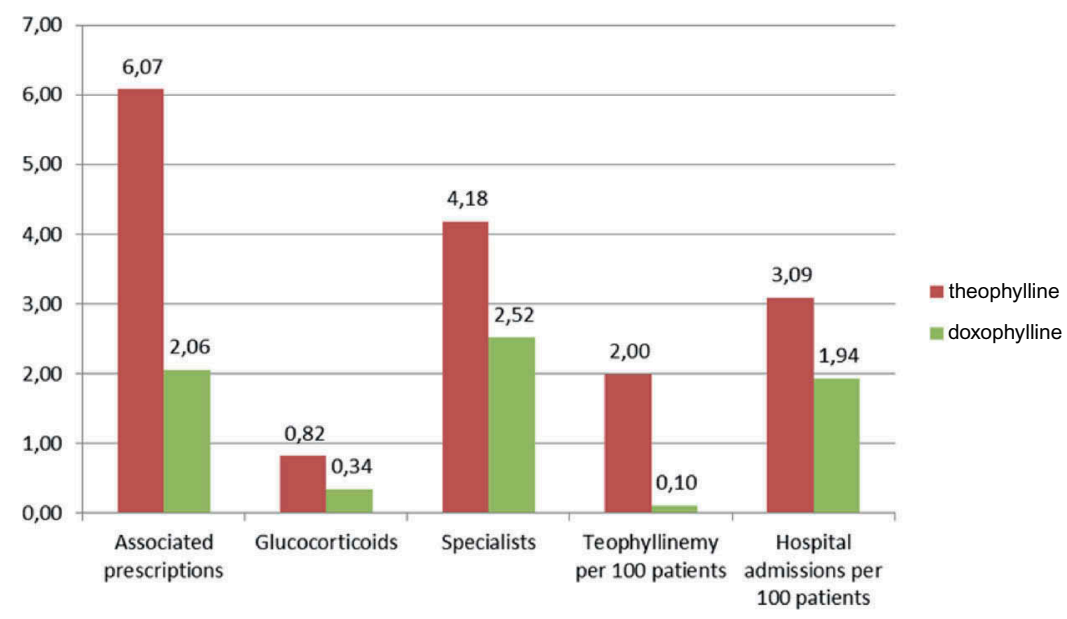

Figure 3. Services associated with treatment with the two drugs ((a) Total population; (b) Patients over 65) - Marche Region $2008-2012$.

6.07 for theophylline and 2.06 for doxophylline, with a reduction of co-prescriptions of $66.0 \%$.

In polypharmacotherapy, the average number of co-prescriptions for female patients in the elderly population is 4.05 for theophylline and 1.39 for doxophylline, with a $65.6 \%$ reduction of co-prescriptions. In male patients versus female ones of the same age, a 93\% increase of average prescription per patient for theophylline (7.82 average co-prescriptions per patient) and $102.9 \%$ for doxophylline (2.83 average co-prescriptions per patient) was observed.

The guidelines indicate the possibility to use glucocorticoids in the asthma or COPD treatment. However, given the scientific evidence of an anti-inflammatory activity of doxophylline [13], the prescription associated with glucocorticoids was analyzed in detail.

As far as the co-prescriptions are concerned, it was observed that the association with glucocorticoids is always higher with theophylline ( 0.7 average co-prescriptions per patient) with respect to doxophylline (0.3 average co-prescriptions per patient) (Figure 3).

The difference of average co-prescription of glucocorticoids per patient in the male population is higher (0.9 and 0.3 prescriptions) than in the female population $(0.6$ and 0.3 ).

Considering that these drugs are mainly prescribed in the elderly population, this association was further analyzed in patients aged over 65. In the elderly population, the co-prescription of glucocorticoids is 0.8 average coprescriptions per patient for theophylline and 0.3 average co-prescriptions per patient for doxophylline: $-58.1 \%$ (Figure 3).

Again, a gender-specific difference in the average co-prescription of glucocorticoids per patient in patients aged over 65 , both associated with theophylline (1.0 in men and 0.6 in women) and doxophylline (0.4 in men and 0.3 in women) may be observed. 
(a) Average yearly cost for associations \pm 30 days (total population)
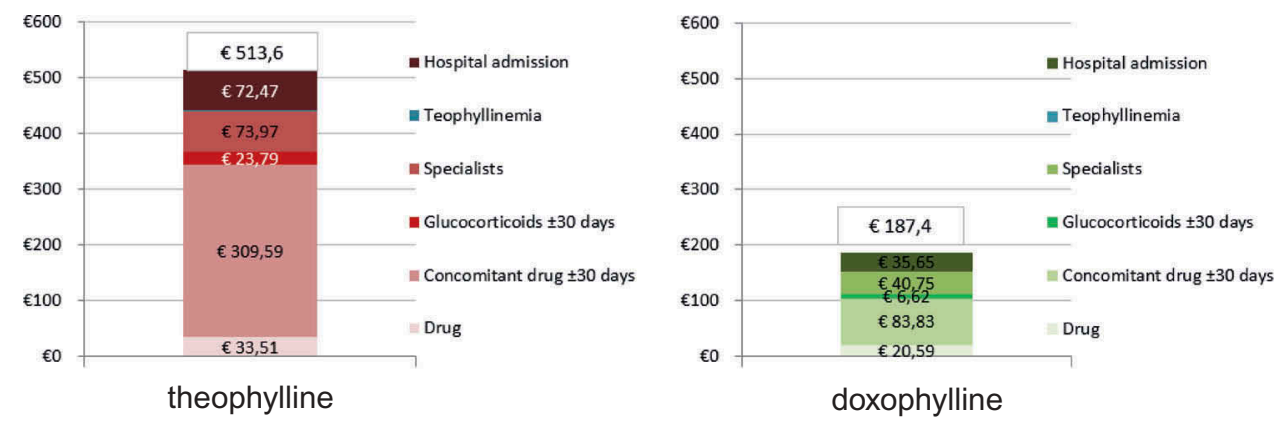

(b) Average yearly cost for associations \pm 30 days (over 65 )
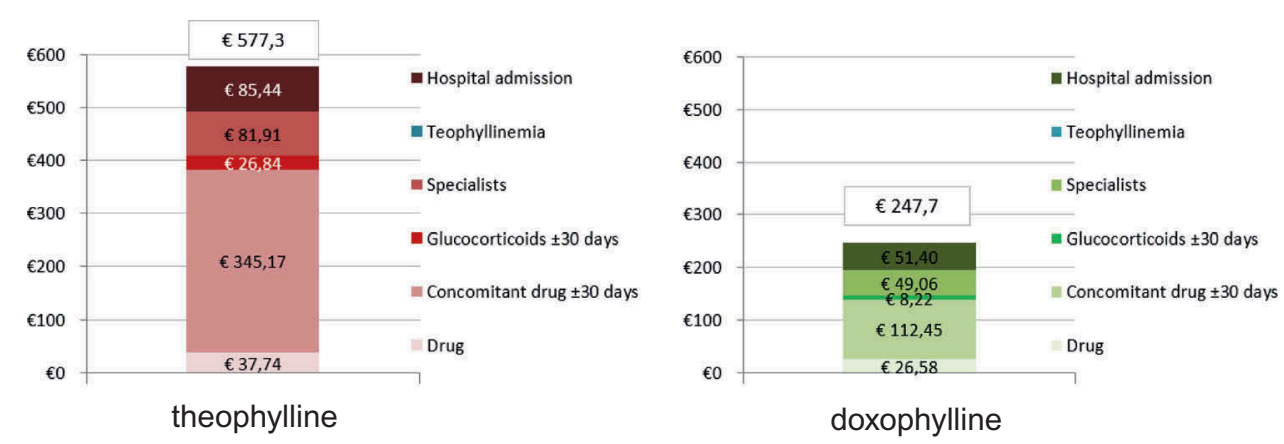

Figure 4. Average yearly cost for associations \pm 30 days ((a) Total population; (b) Over 65 patients) Marche Region 2008-2012.

Comparing the genders, the co-prescription of glucocorticoids was always lower in women with both theophylline and doxophylline.

\subsection{Specialist services associated with the treatment with theophylline or doxophylline}

For each treated patient, the average number of services associated with theophylline (Note 2; Figure 3) was 3.73 for theophylline and 2.05 for doxophylline ( $\left.\mathrm{RR}_{\mathrm{adj}} 0.90 ; 95 \% \mathrm{Cl} 0.85-0.94\right)$.

In the elderly population, these services per treated patient increase to 4.18 for theophylline and 2.52 for doxophylline.

Again, a gender-specific difference between males (4.43 for theophylline and 2.38 for doxophylline) and females (2.95 for theophylline and 1.75 for doxophylline) was observed.

As during the therapy with theophylline a periodical check of its plasma concentration is recommended - although this therapy is considered 'obsolete' and therefore not always used - it was inquired whether it was used during the therapy with the two xanthines. As it may be observed, the number of theophyllinemies per 100 patients was negligible for a therapy with doxophylline (Figure 3).

\subsection{Hospital admissions associated with the treatment with theophylline or doxophylline}

The number of DRG-specific hospital admissions for asthma and COPD observed during both therapies was extremely low: $1.2 / 100$ patients treated with theophylline and $0.6 / 100$ patients treated with doxophylline. The risk of hospitalization within 1 year from first prescription was lower in patients treated with doxophylline compared with theophylline, but not statistically significant $\left(\mathrm{RR}_{\mathrm{adj}} 0.94 ; 95 \% \mathrm{Cl} 0.75-1.17\right)$.

There were no significant differences between the population over 65 and the total one in patients treated with doxophylline $(0.5 / 100$ patient, t-test $p$-value 0.173$)$, while hospitalization rate in patients over 65 treated with theophylline reduced to $0.6 / 100$ (t-test $p<0.001$ ). DRG-specific hospital admissions had a significant gender differential: the number of hospital admissions was $0.3 / 100$ for male patients treated with theophylline and 3.7/100 for female patients (t-test $p<0.001$ ); the number of hospital admissions was $0.2 / 100$ for male patients treated with doxophylline and $1.7 / 100$ for female patients (t-test $p<0.001$ ).

Reducing the period of observation associated with the prescription of methylxanthines ( \pm 5 days), the results of previous analyses were unchanged (data are not reported).

\subsection{Costs associated with the treatment with theophylline or doxophylline}

Considering the services associated with the treatment within \pm 30 days, a net cost difference in the total population was observed, with an average yearly cost of $€ 513.6$ per patient treated with theophylline versus $€ 187.4$ per patient treated with doxophylline (Figure 4). Obviously, in the elderly population (over 65), a higher cost than that of younger population under treatment with both drugs was observed. However, once again the therapy cost with doxophylline ( $€ 247.7$ per patient) was definitely lower than that with theophylline (€577.3 per patient) (Figure 4). 


\section{Discussion}

The information system of the pharmaceutical prescriptions allows us to conduct monitoring studies of the prescriptions and compare the drugs, taking into account the whole therapeutic program of the patient. However, these prescriptions, by nature, do not allow us to identify the therapeutic implications of the administered drugs' effects. Furthermore, they do not allow to compare two groups of completely homogeneous treatment. However, the fact that both doxophylline and theophylline have an overlapping RCP allows to assume that the two drugs may be equally prescribed.

In the population of the Marche region, during the considered 5 year period (2008-2012), the number of patients treated with theophylline was lower than that of patients treated with doxophylline. However, the number of theophylline prescriptions was higher than that of doxophylline. This demonstrates that although methylxanthines are obsolescent in the market, the physicians still consider them a valid tool to monitor respiratory disease symptoms.

The prescription of theophylline resulted always higher than that of doxophylline in males. Conversely, this did not occur in females, regardless of the age segment considered.

The analysis of the association of the two methylxanthines with other drugs highlighted an average number of co-prescriptions per patient definitely higher for theophylline by both sex and age segment. It is observed that when the two methylxanthines are associated with glucocorticoids, these drugs are less necessary when doxophylline is used. This difference is significant both in terms of the average number of treated patients in the whole population ( 0.3 for doxophylline versus 0.7 for theophylline) and only taking into account the prescription in the over 65 age segment ( 0.3 for doxophylline versus 0.8 for theophylline; $-58.1 \%$ of prescriptions). Finally, considering this age segment, it is observed that doxophylline seems to require a higher reduction of glucocorticoids in both men (0.4 for doxophylline versus 1.0 for theophylline) and women ( 0.3 for doxophylline versus 0.6 for theophylline).

This reduced need to indirectly co-prescribe glucocorticoids seems to confirm the anti-inflammatory activity associated with doxophylline in the human being, as demonstrated by Page in vivo [18]. This consumption data is important considering that doxophylline is mainly prescribed to women who experience the highest osteoporosis damage after the corticosteroid therapy $[19,20]$.

The recourse to specialist consultations during the therapy with theophylline was higher in both the total population and the elderly one. Such difference confirms a higher sense of safety in the use of doxophylline by both the physician and the patient. This seems to be confirmed by the fact that although women were prescribed more doxophylline, they were submitted less to specialist consultations. Furthermore, the assumption of a higher safety of doxophylline is confirmed by the fact that the patients being treated with it were detected a negligible plasma drug concentration in periodical checks.

The warning contained in the technical data sheet of this drug recommends a monitoring of its plasma concentration in case there are factors affecting its clearance.
The hospital admissions of the population observed in the group of patients treated with theophylline are higher both when specific DRG (asthma and COPD: 1.2 vs 0.6 for theophylline and doxophylline, respectively) were considered and when all possible DRGs related to potential adverse events (1.9 vs 1.0; theophylline vs doxophylline) were taken into account. No difference was observed when the patient age was considered. In female patients who received the highest number of doxophylline prescriptions, the number of hospital admissions was definitely lower (1.7 vs 3.7 for doxophylline and theophylline, respectively).

Finally, total costs (specific drug, associated drugs including glucocorticoids, specialist visits, plasma monitoring of the specific drug, hospital admissions) incurred in the year following the first prescription show a substantial unit cost difference for the patient. The differential is always in favor of patients being treated with doxophylline, although the cost of this last drug is higher than that of theophylline.

This study shows an important limit that should be taken into account. The administrative data do not allow us to know the patient's health state (including concomitant diseases) and the treated disease (asthma and COPD) at the time of the first prescription. Therefore, there are two possible biases in the patients' treatment.

The first bias could be given by the physician belief that theophylline is more effective than doxophylline. Consequently, the more severe patients were treated with this drug.

This hypothesis could be confirmed by the fact that theophylline-treated patients had higher co-prescriptions, visits, and hospital admissions. The co-prescriptions were needed even in presence of potential higher risk of drug interactions and adverse reactions.

The second bias may be due to the prescriber's belief that doxophylline is safer. Therefore, it was the drug to be prescribed to the more severe patients. The lack of necessity to therapeutic drug monitoring of doxophylline could be more 'accepted' by the patient and certainly less 'worrying' for the prescriber. The anti-inflammatory activity of doxophylline and the reduced need of the glucocorticoid association could explain the lower number of co-prescriptions as well as the less number of visits and hospital admissions.

Unfortunately, administrative data, which do not allow us to know the patient's history at the time of first prescription, make both hypotheses possible.

Finally, a third hypothesis should be taken into account. Since the technical data sheets of the two drugs are identical, it is highly possible that the physicians indistinctly chose theophylline or doxophylline, because they have the same profile of activity [7,10-13,18,21-24].

In conclusion, this analysis undoubtedly demonstrates a significant difference in the unit cost per patient in favor of doxophylline. Although the drug cost is higher, prescribers are recommended to prescribe it instead of theophylline, not only for its higher tolerance and manageability, but also because it reduces the costs associated with COPD and/or asthma treatments. 


\section{Key issues}

- This is the first attempt in our country to identify two groups of patients who were inquired retrospectively and enrolled in the analysis through the respective ATC codes (R03DA04 and R03DA11) and develop an administrative cross linkage database in order to estimate associated drugs, specialist visits, hospital admissions, plasma drug monitoring in real world practice.

- The information system of the pharmaceutical prescriptions allows us to conduct monitoring studies of the prescriptions and compare the drugs, taking into account the whole therapeutic programme of the patient. However, these prescriptions, by nature, do not allow us to identify the therapeutic implications of the administered drugs' effects. Furthermore, they do not allow to compare two groups of completely homogeneous treatment. However, the fact that both doxofylline and teophylline have an overlapping RCP allows to assume that the two drugs may be equally prescribed.

- Total costs (specific drug, associated drugs including glucocorticoids, specialist visits, plasma monitoring of the specific drug, hospital admissions) incurred in the year following the first prescription, show a substantial unit cost difference for the patient. The differential is always in favour of patients being treated with doxofylline, although the cost of this last drug is higher than that of teophylline.).

\section{Acknowledgements}

This work was supported by an unrestricted grant from ABC Farmaceutici Italy.

\section{Funding}

This paper was not funded.

\section{Declaration of interest}

FS Mennini was consultant for ABC Farmaceutici. AP Caputi was consultant for $A B C$ Farmaceutici. The authors have no other relevant affiliations or financial involvement with any organization or entity with a financial interest in or financial conflict with the subject matter or materials discussed in the manuscript apart from those disclosed.

\section{References}

1. Halbert RJ, Natoli JL, Gano A, et al. Global burden of COPD: systematic review and meta-analysis. Eur Respir J. 2006;28:523-532.

2. Gan WQ, FitzGerald JM, Carlsten C, et al. Associations of ambient air pollution with chronic obstructive pulmonary disease hospitalization and mortality. Am J Respir Crit Care Med. 2013;187:721-727.

3. Salvi SS, Barnes PJ, Tiruvoipati R, et al. Chronic obstructive pulmonary disease in nonsmokers. Lancet. 2009;374:733-743.

4. Eisner MD, Anthonisen N, Coultas D, et al. An official American Thoracic Society public policy statement: novel risk factors and the global burden of chronic obstructive pulmonary disease. Am J Respir Crit Care Med. 2010;182:693-718.
5. Mannino DM, Buist AS. Global burden of COPD: risk factors, prevalence, and future trends. Lancet. 2007;370:765-773.

6. Global Initiative for Chronic Obstructive Lung Disease, Pocket Guide to COPD Diagnosis Management and Prevention, 2017, Report.Available from: http://goldcopd.org/wp-content/uploads/ 2016/12/wms-GOLD-2017-Pocket-Guide.pdf

7. Grossi E, Biffignandi P, Franzone JS, et al. Doxophylline: drug profile and review of clinical trials. Eur Rev Med Pharmacol Sci. 1988;10:18.

8. Franzone JS, Cirillo R, Barone D, et al. Doxophylline and theophylline are xanthines with partly different mechanisms of action in animals. Drug Explt Clin Res. 1988;14:479-489.

9. Franzone JS, Cirillo R, Biffignandi P. Doxophylline exerts a prophylactic effect against bronchoconstriction and pleurisy induced by PAF. Eur J Pharmacol. 1989;165:269-277.

10. Bucca C, Rolla G, Fonzo D, et al. Acute clinical-pharmacological findings in obstructive pneumopathy following 2(7, -theophyllinmethyl) 1, 3-dioxolane (doxophylline). Int J Clin Pharm Res. 1982;4:101-103.

11. Melillo G, Balzano G, Jodice F, et al. Treatment of reversible chronic airways obstruction with doxophylline compared with slow-release theophylline: a double-blind, randomized, multicentre trial. Int J Clin Pharm Res. 1989;9:397-405.

12. Dolcetti A, Osella D, Carnuccio C, et al. Study of effects of intravenous use of doxophylline, a new methylxanthine derivative, in the treatment of patients affected by chronic obstructive pulmonary disease. Minerva Pneumologica. 1988;27:211-215.

13. Goldstein MF, Cherwinsky P. Efficacy and safety of doxophylline compared to theophylline in chronic reversible asthma - a doubleblind randomized placebo-controlled multicentre clinical trial. Med Sci Monit. 2002;8:297-304.

14. Dini FL, Cogo R. Doxophylline: a new generation xanthine bronchodilator derived and major cardiovascular side effects. Curr Med Res Opin. 2001;16:258-268.

15. Sacco C, Braghiroli A, Grossi E, et al. The effects of doxophylline versus theophylline on sleep architecture in COPD patients. Monaldi Arch Chest Dis. 1995;50:98-103.

16. Franzone JS, Cirillo R, Reboani MC. Doxophylline differs from methylxanthines in its movement of cytosolic calcium. Int J Tissue React. 1991;13:131-138.

17. van Mastbergen J, Jolas $T$, Allegra $L$, et al. The mechanism of action of doxophylline is unrelated to HDAC inhibition, PDE inhibition or adenosine receptor antagonism. Pulm Pharmacol Ther. 2012;25:55-61.

18. Page CP. Doxophylline: a "novofylline". Pulm Pharmacol Ther. 2010;23:231-234.

19. Cogo R, Castonuovo A. Effects of oral doxophylline on inflammatory changes and altered cell proliferation in chronic obstructive bronchitis. Eur Rev Med Pharmacol Sci. 2000;4:15-20.

20. Israel E, Banerjee TR, Fitzmaurice GM, et al. Effects of inhaled glucocorticoids on bone density in pre-menopausal women. $\mathrm{N}$ Engl J Med. 2001;345:941-947.

21. Margay SM, Farhat S, Kaur S, et al. To study the efficacy and safety of doxophylline and theophylline in bronchial asthma. J Clin Diagn Res. 2015;9:FC05-FC08.

22. Lal D, Manocha S, Ray A, et al. Comparative study of the efficacy and safety of theophylline and doxofylline in patients with bronchial asthma and chronic obstructive pulmonary disease. J Basic Clin Physiol Pharmacol. 2015;26:443-451.

23. Rajanandh MG, Nageswari AD, llango K. Pulmonary function assessment in mild to moderate persistent asthma patients receiving montelukast, doxofylline, and tiotropium with budesonide: a randomized controlled study. Clin Ther. 2014;36:526-533.

24. Wang T, Luo G, Hu Y, et al. Comparative study on the efficacy of tiotropium bromide inhalation and oral doxofylline treatment of moderate to severe stable chronic obstructive pulmonary disease. J Huazhong Univ Sci Technolog Med Sci. 2011;31:614-618. 


\section{Appendix}

Note 1. DRGs potentially associated with asthma and/or COPD or to possible adverse events (cardiovascular, gastrointestinal, and neurological events) of the drug.

- DRG 96 (bronchitis and asthma, age $>17$ with CC)

- DRG 97 (bronchitis and asthma, age $>17$ without CC)

- DRG 98 (bronchitis and asthma, age <18)

- DRG 99 (respiratory signs and symptoms with CC)

- DRG 100 (respiratory signs and symptoms without (C)

- DRG138 (arrhythmia and cardiac conduction alteration with CC)

- DRG139 (arrhythmia and cardiac conduction alteration without CC)

- DRG174 (gastrointestinal bleeding with CC)

- DRG182 (esophagitis, gastroenteritis, and miscellaneous of digestive system disorders, age $>17$ with (C)

- DRG183 (esophagitis, gastroenteritis, and miscellaneous of digestive system disorders, age $>17$ without (C)

- DRG175 (gastrointestinal bleeding without CC)

- DRG024 (convulsions and cephalalgia, age >17 with CC)

- DRG025 (convulsions and cephalalgia, age >17 no CC)

- DRG564 (cephalalgia, age >17)

Note 2. Codes of tariffs in the range of fees for specialist visits potentially associated with therapies being analyzed.

\section{- 33.22 (bronchoscopy with optical fibers)}

- 34.24 (bronchial biopsy [endoscopic])

- 38.98.1 (contrast medium injection for radiotherapic simulation TC)

- 38.99.2 (contrast medium injection for radiotherapic simulation RM)

- 45.13 (esophagogastroduodenoscopy [EGD])

- 87.41 (chest [CT] scan)

- 87.44.1 (routine chest $x$-ray, NAS)

- 89.03 (medical history and evaluation, defined overall)

- 89.07 (consultation, defined overall)

- 89.13 (neurological examination)

- 89.37.1 (simple spirometry)

- 89.37.2 (global spirometry)

- 89.37.4 (pharmacological bronchodilator test)

- 89.37.5 (bronchodynamic test with specific and nonspecific bronchoconstrictor)

- 89.37.6 (bronchodynamic test with specific bronchoconstrictor)

- 89.38.1 (airway resistance)

- 89.38.2 (global spirometry with plethysmography)

- 89.38.3 (alveolar-capillary diffusion of $\mathrm{CO}_{2}$ )

- 89.38.4 (static and dynamic pulmonary compliance)

- 89.38.5 (breathing pattern at rest)

- 89.38.6 (evaluation of ventilation and expired gases and related parameters)

- 89.38.7 (maximum inspiratory and expiratory pressure)

- 89.38.8 (ventilation distribution test with nonradioactive gases)

- 89.38.9 (PO.1 determination)

- 89.41 (cardiovascular stress test with mobile springboard)

- 89.43 (cardiovascular stress test with bicycle ergometer)

- 89.44.1 (cardiorespiratory stress test)

- 89.44.2 (walk test)

- 89.50 (dynamic electrocardiogram)

- 89.52 (electrocardiogram)

- 89.54 (electrocardiographic monitoring)

- 89.61.1 (24 h monitoring of blood pressure)

- 89.65.1 (systemic arterial blood gas test)

- 89.65.2 (blood gas test during high-concentration $\mathrm{O}_{2}$ respiration)

- 89.65.3 (blood gas test during low-concentration $\mathrm{O}_{2}$ respiration)

- 89.65.4 $\left(\mathrm{O}_{2}\right.$ and $\mathrm{CO}_{2}$ transcutaneous monitoring)

- 89.65.5 (noninvasive monitoring of arterial saturation)

- 89.65.6 (blood gas test before and after hyperventilation)

- 89.7 (general examination)

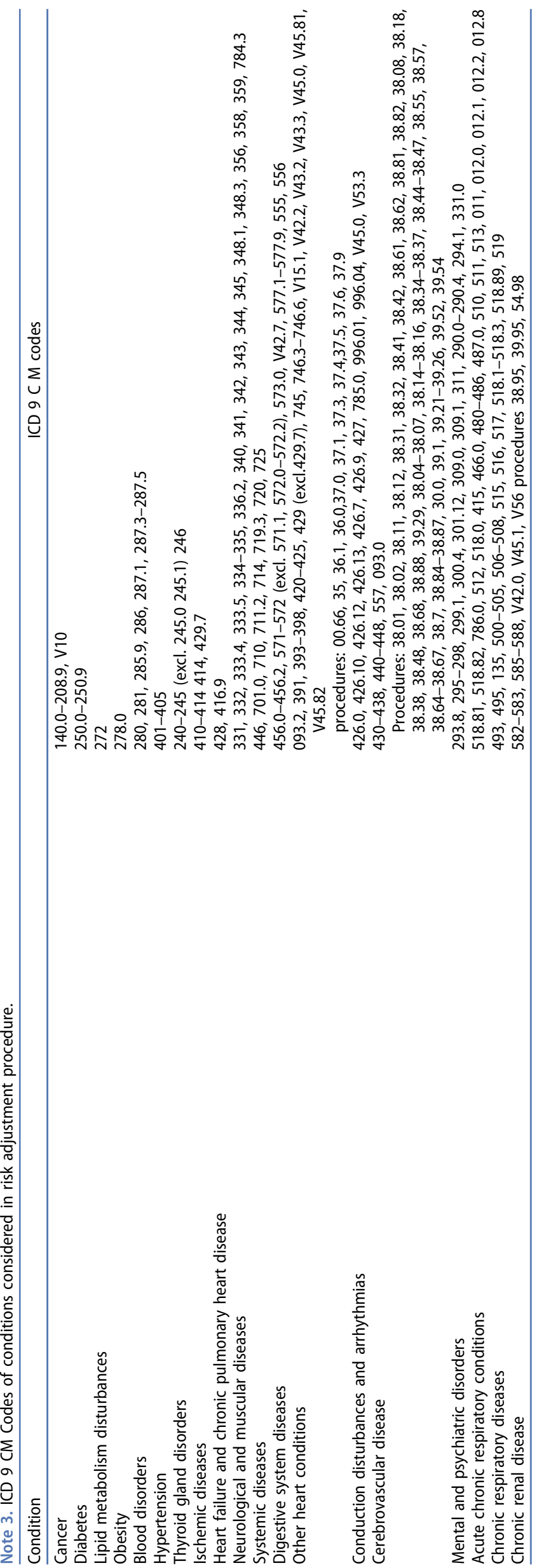

